\title{
Renal tubular leakage complicating microcephalic osteodysplastic primordial dwarfism
}

\author{
J Eason, C M Hall, J Q Trounce
}

\begin{abstract}
We describe a male infant with phenotypic and radiological features of microcephalic osteodysplastic primordial dwarfism type I/III. He showed severe osteoporosis and biochemical derangement owing to renal tubular leakage, which has not previously been reported in this condition. He died aged 5 months.
\end{abstract}

( $($ Med Genet 1995;32:234-235)

We describe a male infant with microcephalic osteodysplastic primordial dwarfism. The purpose of this paper is to report the previously unrecognised complication of renal tubular leakage.

\section{Case report}

Our patient was the second child born to healthy, non-consanguineous parents. The mother, aged 39 years, had no history of miscarriages. She was a non-smoker and on no medication during pregnancy. Increasingly severe intrauterine growth retardation was noted on antenatal ultrasound scanning from 17 weeks onwards and maternal alphafetoprotein level was raised. Cordocentesis showed a normal karyotype. Labour was induced at 36 weeks owing to the growth re-

Birth weight was $1260 \mathrm{~g}$, length $40 \mathrm{~cm}$, and occipitofrontal circumference $27 \mathrm{~cm}$ (all parameters well below the $3 \mathrm{rd}$ centile). He had large and protruding eyes and nose, micrognathia, low set, simple ears, and a short neck (fig 1). The hands were relatively broad with

Department of

Paediatrics, The Royal

Alexandra Hospital

for Sick Children,

Dyke Road, Brighton

BN1 3JN, UK

$\mathrm{J}$ Eason

J Q Trounce

Department of

Radiology,

The Hospital for

Sick Children,

Great Ormond Street, London WC1N 3JH,

UK

C M Hall

Correspondence to: Dr Trounce.

Received 27 October 1994 Revised version accepted for publication

21 November 1994

Figure 1 Profile at 5 weeks showing protuberant eyes, prominent occiput, and micrognathia. Note also the sparse eyebrows and lashes but normal scalp hair. tardation and normal vaginal delivery ensued.

short fingers (all of similar length) (fig 2) and bilateral single palmar creases. He showed a lack of subcutaneous fat and sparse eyebrows and lashes, but normal growth of scalp hair.

The neonatal course was complicated by recurrent apnoea, hyperbilirubinaemia, hyperglycaemia, and hyponatraemia. Aged 9 weeks he had recurrent seizures which responded to phenobarbitone. EEG showed no focal abnormality. He showed developmental delay with no social smile detected and dependence on tube feeding throughout his life. His postnatal weight gain was satisfactory but length and head circumference deviated further below the 3 rd centile.

Radiographs showed several skeletal abnormalities. The iliac wings were short and the acetubular roofs horizontal and irregular (fig 3). There was an increase in the intervertebral spaces with mild flattening of the vertebral bodies. The upper femora were broad. The clavicles were long. The metacarpals and phalanges were short and broad with pronounced cupping of the proximal ends. The metaphyses were flared and showed some irregularity. The anterior fontanelle was patent but extremely small. Absence of ossification of the epiphyses at the knee and foot suggested severe growth retardation. There was generalised osteoporosis (fig 3).

Blood and urine tests for intrauterine infection were negative. Karyotype confirmed $46, \mathrm{XY}$ (including skin fibroblasts to exclude mosaicism). Random growth hormone level was $7.9 \mathrm{mU} / \mathrm{l}$, insulin level $<25 \mathrm{pmol} / \mathrm{l}$, and $\mathrm{C}$ peptide $<75 \mathrm{pmol} / 1$. He also showed normal thyroid function, plasma cortisol, blood amino acids, lactate and pyruvate, immunoglobulins, urinary organic acids, urine culture, and renal

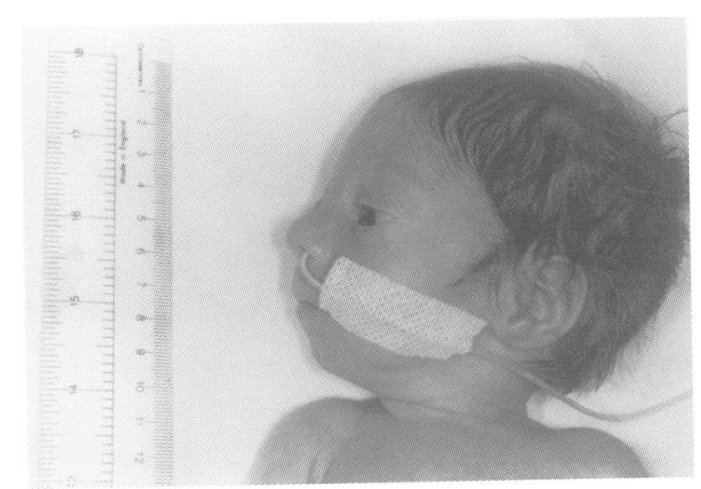

Figure 2 Dorsal aspect of both hands showing the broad appearance with short fingers, each of similar length. 


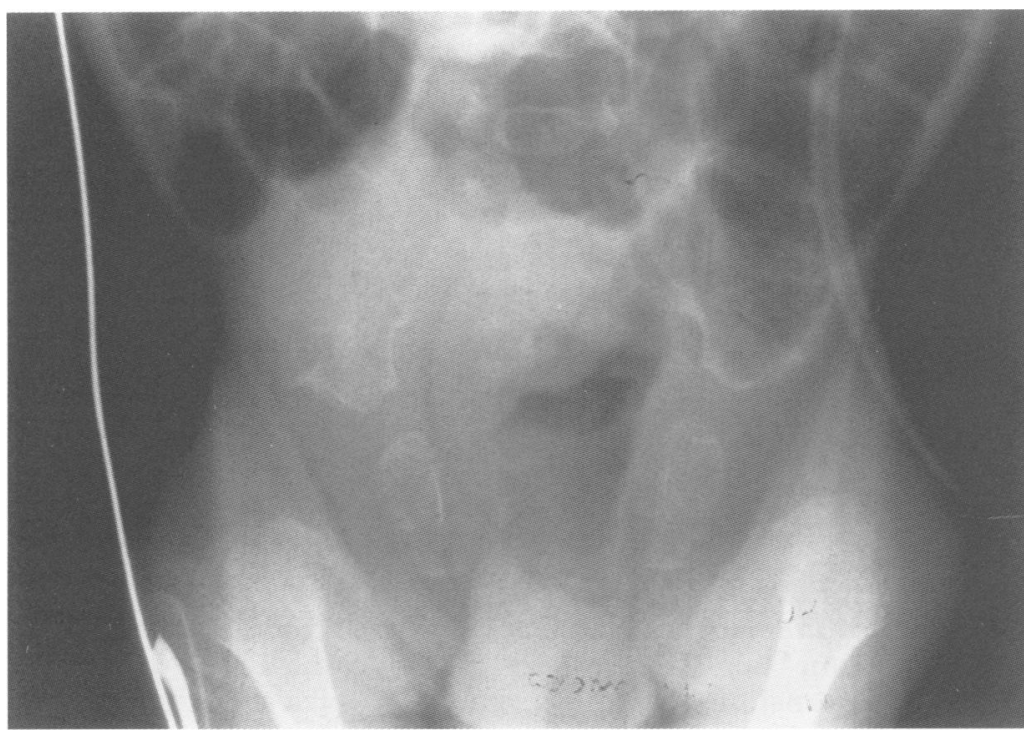

Figure 3 Radiograph showing short iliac wings and horizontal, irregular acetabular roofs. The upper femora are broad. Note the severe generalised osteoporosis.

tract ultrasound. Early cranial ultrasound was normal but aged 10 weeks showed cerebral atrophy.

He developed persistent hyponatraemia, hypokalaemia, hypocalcaemia, and hypo-phosphataemia. He was not acidotic. Investigations showed a renal tubular leak of amino acids (generalised), protein, glucose, sodium, potassium, calcium, and phosphate. Large doses of supplements (potassium dihydrogen phosphate, sodium hydrogen phosphate, and potassium chloride) were required.

He eventually died of a chest infection aged 5 months. Permission for necropsy was declined.

\section{Discussion}

In a series of papers Majewski et $a l^{1-3}$ defined three main groups of microcephalic osteodysplastic primordial dwarfism distinct from Seckel syndrome. Winter et al suggested that types I and III were very similar and the $x$ ray differences may be age dependent. Meinecke and Passarge ${ }^{5}$ suggested that the term "type III" should be abandoned altogether leaving only the two types. As well as extreme growth retardation and microcephaly our patient showed characteristic facial features of microcephalic osteodysplastic primordial dwarfism type I/III (protuberant eyes, micrognathia, prominent occiput, and low set ears). The radiological changes were typical apart from the marked osteoporosis. Our infant displayed the previously unreported feature of a generalised renal tubular leak. He showed persistent hypokalaemia despite supplements and needed a very high level of sodium input to maintain a normal serum level. The calcium and phosphate loss probably caused his osteoporosis. The two cases reported by Meinecke and Passarge ${ }^{5}$ showed normal urinary amino acids. Our infant showed early hyperglycaemia like that reported by Van Maldergem et $a l^{6}$ Glucose intolerance with glycosuria is a recognised feature of certain dwarfing syndromes such as leprechaunism. However, our case showed persistent glycosuria after the blood sugar level normalised, suggesting renal tubular leakage. Unilateral hydronephrosis has been reported ${ }^{7}$ but our baby had a normal renal tract ultrasound. Unfortunately our patient did not undergo necropsy. Winter et $a l^{4}$ reported microscopic abnormalities of the kidney with focal dilatation of the proximal tubules and fibrin deposits occluding the capillaries of a few glomeruli.

We cannot explain this new finding but the knowledge of its existence adds to the complex list of problems this syndrome entails. Its recognition carries important therapeutic implications.

The authors are grateful to Mrs Wendy Jones for typing the manuscript and the Department of Medical Illustration, Royal Sussex County Hospital, Brighton, for the photographs.

1 Majewski F, Goecke T. Studies of microcephalic primordia dwarfism I. Approach to a delineation of the Seckel syndwarism I. Approach to a delineation

2 Majewski F, Ranke M, Schinzel A. Studies of microcephalic primordial dwarfism II. Osteodysplastic primordial primordial dwarfism II. Osteodysplastic prim

3 Majewski F, Stoeckenius M, Kemperdick H. Studies of microcephalic primordial dwarfism III. An intrauterine dwarf with platyspondyly and anomalies of pelvis and claviclesosteodysplastic primordial dwarfism type III. $\mathrm{Am} \mathcal{f} \mathrm{Med}$ Genet 1982;12:37-42.

4 Winter RM, Wigglesworth J, Harding BN. Osteodysplastic primordial dwarfism: report of a further patient with manifestations similar to those seen in patients with types I and III. Am $\mathcal{F}$ Med Genet 1985;21:569-74.

5 Meinecke P, Passarge E. Microcephalic osteodysplastic primordial dwarfism type I/III in sibs. 7 Med Genet 1991;28: 795-800.

6 Van Maldergem L, Gillerot Y, Godhaird M, Nemec E, Koulischer L. Primordial osteodysplastic dwarfism type $I$ in association with corneal clouding: evidence for autosomal

7 Meinecke P, Schaefer E, Wiedemann HR. Microcephalic osteodysplastic primordial dwarfism: further evidence for identity of the so-called types I and III. Am 7 Med Genet 1991;39:232-6. 